\title{
Modulation of Dendritic Cells for Tolerance Induction*
}

\author{
Holger Hackstein \\ Institute for Clinical Immunology and Transfusion Medicine, Justus-Liebig University Gießen, Germany
}

\section{Key Words}

Dendritic cells · Antigen-presenting cells · Alloimmunity

\section{Summary}

Dendritic cells (DC) play a critical role as initiators and modulators of adaptive immune responses. There is increasing evidence that $\mathrm{DC}$ have potent abilities to tolerize and delete $T$ cells in an antigen-specific manner. Immature or semi-mature DC generated in the laboratory can suppress autoimmunity or alloimmunity. With emphasis on the pharmacological modulation of DC, we herewith provide an update on current strategies and concepts to promote the tolerogenic potential of DC for therapy of transplant rejection and autoimmune disease.

\section{Introduction}

Dendritic cells (DC) are uniquely well-equipped antigen (Ag) presenting cells that initiate and regulate immune responses. DC play a dualistic role in the regulation of immune responses. They initiate adaptive immunity by the activating naive lymphocytes and are powerful stimulators of natural killer cells - the crucial cellular instigators of the innate immune system. Furthermore, DC induce central and peripheral tolerance by mechanisms such as deletion, anergy and induction of

*Dedicated to Prof. Dr. Peter Hanfland, Bonn, on the occasion of his 65th birthday.

\section{Schlüsselwörter}

Dendritische Zellen · Antigen-präsentierende Zellen .

Autoimmunität · Alloimmunität

\section{Zusammenfassung}

Dendritischen Zellen (DZ) kommt eine entscheidende Rolle als Initiatoren und Modulatoren adaptiver Immunantworten zu. Es gibt zunehmende Beweise, dass DZ ein hohes Potential besitzen, immunregulatorische T-Zellen zu induzieren. Im Labor hergestellte unreife oder semireife DZ sind in der Lage, Auto- und Alloimmunität zu unterdrücken. Mit Betonung der pharmakologischen Modulation von DZ geben wir hiermit einen Überblick über aktuelle Strategien und Konzepte zur Förderung des tolerogenen Potentials der DZ in der Behandlung von Abstoßungsreaktionen und Autoimmunkrankheiten. regulatory lymphocytes [1]. Attention has long been focused on the exceptional ability of these professional antigen-presenting cells (APC) to stimulate T-cell and B-cell mediated responses. Recently, evidence has emerged concerning the inherent tolerogenicity of DC in the periphery [2,3]. Mechanisms whereby DC can promote peripheral tolerance are under intensive investigation. These studies have important implications for the therapy of autoimmune disorders and allograft rejection. DC are extremely well equipped for their role in innate and adaptive immunity. They are unrivaled in their ability to capture macromolecules via macropinocytosis and mannose receptor-mediated endocytosis into intracellular MHC class II-rich compartments [4]. Following Ag uptake and activation, DC migrate from the periphery to secondary lymphoid tissue, redistribute MHC-Ag complexes to the cell

\begin{tabular}{ll}
\hline KARGER & ๑ 2006 S. Karger GmbH, Freiburg \\
$\begin{array}{l}\text { Fax +49 76145207 14 } \\
\begin{array}{l}\text { E-mail Information@Karger.de } \\
\text { www.karger.com }\end{array}\end{array}$ & $\begin{array}{l}\text { Accessible online at: } \\
\text { www.karger.com/tmh }\end{array}$
\end{tabular}


Fig. 1. Current model of DC maturation and impact on T-cell immunity. Immature DC preferentially induce T-cell anergy and are characterized by low expression of MHC class II, costimulatory molecules and no production of pro-inflammatory cytokines. In contrast to immature DC, semi-mature DC are characterized by high expression of MHC class II and costimulatory molecules and promote the generation of regulatory $\mathrm{T}$ cells and tolerance. Fully mature DC expressing high levels of MHC class II, costimulatory molecules and pro-inflammatory cytokines are required for the induction of T-cell immunity.

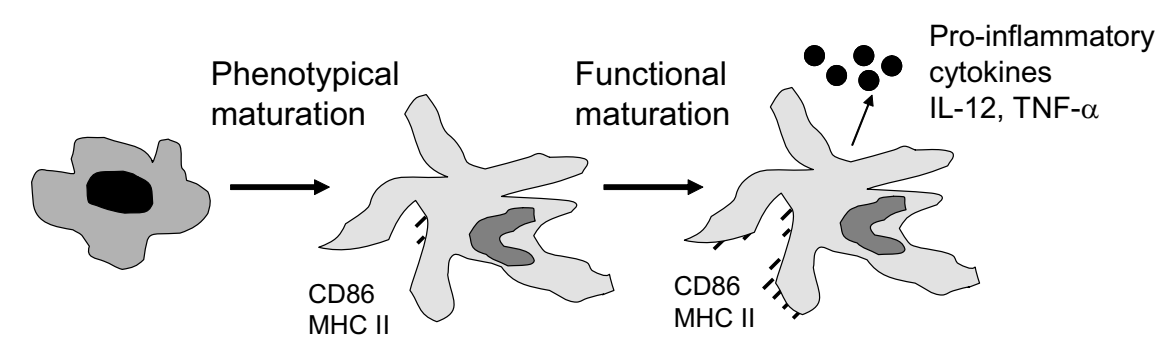

$\downarrow$

T-cell anergy

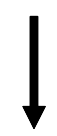

Regulatory T cells
T-cell immunity surface and upregulate surface expression of costimulatory (CD80, CD86) and other molecules that promote DC survival and DC/T-cell clustering (CD40, RANK, CD54, CD58) [1]. The process of maturation also includes the production of high amounts of the pro-inflammatory cytokines IL-12 and TNF- $\alpha$ converting DC into very powerful T-cell priming APC (fig. 1). In addition to the well known immunostimulatory capacity of mature DC, an increasing number of publications have described the immunoregulatory capacity of immature and semi-mature DC [5]. Immature DC induce T-cell anergy and are characterized by low surface expression of MHC class II, costimulatory molecules and the pro-inflammatory cytokines IL-12 and TNF- $\alpha[1,6,7]$. In contrast, so-called semimature DC are characterized by high expression of MHC class II and costimulatory molecules and low or negative production of IL-12 and TNF- $\alpha$ [5]. Semi-mature DC have been suggested to have important immunoregulatory functions and induce CD4+ regulatory T cells in vitro and in vivo [5].

\section{Update on Current Strategies to Promote DC Tolerogenicity}

Currently, two different approaches for the enhancement of the tolerogenic properties of DC are under investigation. One involves the use of immature DC, the other the use of semimature DC (fig. 1). Jonuleit et al. [8] have shown that repetitive in vitro stimulation of allogeneic $\mathrm{T}$ cells with immature DC leads to the generation of non-proliferating, IL-10 producing T regulatory (Treg) cells. Proliferation of these T cells could not be restored by exogenous IL-2, and the proliferation of type 1 helper T (Th1) cells was inhibited in a contact-de- pendent, but non-Ag-specific manner. In agreement with these findings, Dhodapkara et al. [9] subcutaneously injected immature autologous monocyte-derived DC pulsed with influenza matrix peptide and keyhole limpet hemocyanin into 2 human volunteers. As a result, they observed Ag-specific inhibition of CD8+ T-cell killing activity and the appearance of peptide-specific IL-10-producing T cells, accompanied by a decrease in IFN- $\gamma$-producing T cells. Two remarkable findings emerged from these studies. First, both studies associated the appearance of DC-induced Treg cells with production of IL-10, but not IL-4. Second, the loss of T-cell killing activity was not due to a decline in peptide-specific T cells, indicating immune regulation rather than deletion of effector cells.

\section{Pharmacological Modulation of DC Maturation as an Approach to Promote Tolerance Induction}

Based on the findings that modulation of DC maturation is critical for the tolerogenic or immunogenic capacity of DC, one strategy to promote the tolerogenicity of DC is the use of drugs that suppress DC maturation. This concept is reasonable, since an increasing number of publications demonstrated that DC represent emerging pharmacological targets of classical and novel immunosuppressive drugs [10]. For many years, $\mathrm{T}$ cells have been considered the main targets of numerous immunosuppressive/anti-inflammatory drugs. The discovery that several immunosuppressive/anti-inflammatory agents potently inhibit DC immunogenicity has provided not only new insight into the immunopharmacology of these substances, but also offers novel strategies for the manipulation of DC for tolerance induction [10]. 
$1,25(\mathrm{OH})_{2} \mathrm{D}_{3}$ - the biologically active metabolite of vitamin $\mathrm{D}_{3}$ - or its analog 1a,25(OH)2-16-ene-23-yne-26,27-hexafluoro-19-nor-vitamin D3 (D3-analog) inhibit the maturation of human monocyte-derived DC [11-13] and mouse bone marrow(BM)-derived DC in vitro [14]. DC treated with $1,25(\mathrm{OH})_{2} \mathrm{D}_{3}$ or D3-analog are poor stimulators of allogeneic $\mathrm{T}$ cells, show impaired IL-12, but increased IL-10 secretion and exhibit enhanced endocytic activity [11-14]. In vitamin D receptor (VDR) knock out (KO) mice the inhibitory effects of $1,25(\mathrm{OH})_{2} \mathrm{D}_{3}$ and the $\mathrm{D} 3$-analog on DC maturation and T-cell stimulatory function were absent [14]. Interestingly, VDR KO mice show hypertrophy of subcutaneous lymph nodes, as well as increased numbers of mature DC in lymph nodes, suggesting a physiological role of the $1,25(\mathrm{OH})_{2} \mathrm{D}_{3}$-VDR loop in DC homeostasis and maturation in vivo [15]. Pretreatment of mice with vitamin $\mathrm{D}_{3}$-exposed donor $\mathrm{DC}$ prolongs skin graft survival [15].

Two independent studies provided recent evidence that aspirin (the most commonly used analgesic and anti-inflammatory drug) profoundly suppresses the maturation and T-cell stimulatory function of human monocyte-derived and mouse BM-derived DC $[16,17]$. Aspirin-treated DC failed to induce cell-mediated contact hypersensitivity reactions in vivo [17], indicating that exposure to aspirin is a highly effective and inexpensive way of manipulating the immunostimulatory potential of DC that may find clinical application. In contrast to salicylates, corticosteroids not only suppress DC maturation but also potently inhibit DC differentiation both in vitro $[18,19]$ and in vivo [20]. Corticosteroid-treated human monocyte-derived or mouse BM-derived DC promote the generation of IL-5- and IL-10-producing $\mathrm{T}$ cells while inhibiting IFN- $\gamma$ secretion and therefore favor Th2/Treg immune responses [21, 22]. Future studies are necessary to determine whether ex vivo treatment of DC with corticosteroids and subsequent injection facilitate the expansion of Th2/Treg cells in vivo.

\section{Mycophenolate Mofetil (MMF), Cyclosporine (CsA) and Tacrolimus (FK506)}

MMF is a reversible inhibitor of inosine monophosphate dehydrogenase (IMPD) which is critical for the de novo synthesis of guanosine and deoxyguanosine molecules necessary for the generation of RNA and DNA [23]. MMF is thought to selectively target the proliferation of $\mathrm{B}$ and $\mathrm{T}$ cells that depend to a greater extent on the de novo synthesis of purines than other cells [24]. Mehling et al. [25] reported that MMF directly affects DC maturation and impairs their capacity to induce a cell-mediated immune response in vivo. The findings of this study indicate a novel role of the enzyme IMPD in DC activation, which was recently confirmed by another group [26]. As regards the calcineurin inhibitors CsA and FK 506, Lee et al. [27] suggested that CsA interfered with DC maturation via $\mathrm{NF}-\kappa \mathrm{B}$ inhibition, while other studies have failed to demonstrate significant effects of CsA on the maturation of monocyte-derived DC [19] or on epidermal Langerhans cell function [28]. Future studies analyzing the effects of CsA on DC maturation and function in vivo are necessary to clarify this issue. Interestingly, Chen et al. [29] reported, that CsA inhibits DC migration through inhibition of CC-chemokine receptor 7 expression. With respect to the calcineurin inhibitor FK-506, 2 studies have indicated no significant effects on DC maturation $[19,30]$. However, since tacrolimus suppresses TNF- $\alpha$ production by DC [19] and DC T-cell stimulatory capacity [31, 32], there are reasons to believe that this substance also targets functional DC maturation. However, the precise molecular mechanisms remain elusive.

\section{Rapamycin}

Rapamycin is a bacterial macrolide antibiotic with potent immunosuppressive action introduced in recent years as anti-rejection therapy in organ transplantation [33]. Rapamycin, like FK506, binds intracellularly to FK506 binding proteins. However, unlike FK506, it inhibits the function of the serine/threonine kinase target of RAPA (mammalian (m) TOR) [34]. mTOR is a common effector protein shared by many signaling pathways. Inhibition of mTOR results in suppression of cytokine-driven cell proliferation, ribosomal protein synthesis, translation initiation and cell cycle arrest in the G1 phase [34, 35].

In addition to its suppressive effect on lymphocytes, rapamycin suppresses the generation of GM-CSF-expanded human monocyte-derived DC in vitro and the generation of fms-like Flt3L(tyrosine 3 kinase ligand)-expanded DC in mice in vivo [36-38]. Moreover, we identified rapamycin as the first clinically relevant substance that inhibits DC antigen uptake in a maturation-independent manner [39]. At low concentrations, rapamycin impairs macropinocytosis and mannose receptor-mediated endocytosis of mouse BM-derived DC and human monocyte-derived DC. Furthermore, inhibition of DC antigen uptake by rapamycin was confirmed with human monocyte-derived DC and after in vivo administration of the drug [37, 39].

\section{Sanglifehrin A (SFA)}

SFAs, originally described by Sanglier et al. [40] and Fehr et al. [41], are produced by the actinomycetes strain Streptomyces A92-308110 and belong to a novel family of immunophilin-binding ligands. Although SFA, like CsA, binds with high affinity to cyclophilin, it unlike the latter does not inhibit the activity of the calcineurin phosphatatase [42]. Com- 
Table 1. Treatment of allograft rejection and autoimmune diseases with DC without additional immunosuppression

\begin{tabular}{|c|c|c|c|}
\hline DC type and modification & Route & Species & Biological effect \\
\hline Semi-mature DC (IL-10, TGF- $\beta$, LPS) & i.v. & mouse & $\begin{array}{l}\text { protection from graft-versus-host disease in } \\
\text { experimental bone marrow transplantation[57] }\end{array}$ \\
\hline GM-CSF cultured immature myeloid donor DC & i.v. & mouse & prolonged or indefinite heart allograft survival $[46,49]$ \\
\hline $\mathrm{NF}-\kappa \mathrm{B}$ ODN treated myeloid donor DC & i.v. & mouse & prolonged heart allograft survival [47] \\
\hline Fas ligand transfected myeloid donor DC & i.p. & mouse & prolonged heart allograft survival [48] \\
\hline Adenovirus IL-10/TGF- $\beta$ transduced myeloid donor DC & p.v. & mouse & prolonged kidney allograft survival [51] \\
\hline Rapamycin exposed alloantigen pulsed host-DC & i.v. & mouse & $\begin{array}{l}\text { prolonged heart allograft survival [50] } \\
\text { biological effect on autoimmune diseases }\end{array}$ \\
\hline Adenovirus IL-4 transduced DC & i.v. & mouse & suppression of collagen-induced arthritis [62] \\
\hline MBP pulsed autologous myeloid DC & s.c. & rat & prevention of MBP-induced EAE [53] \\
\hline $\begin{array}{l}\text { GM-CSF cultured ( } \pm \text { IL- } 4 ; \pm \text { islet-autoantigen pulsed }) \\
\text { autologous myeloid DC }\end{array}$ & i.v. & mouse (NOD) & decreased incidence of type-1 diabetes [54] \\
\hline Ex vivo IFN- $\gamma$ stimulated autologous splenic DC & i.p. & mouse (NOD) & decreased incidence of type-1diabetes [55] \\
\hline Semi-mature DC (TNF- $\alpha)$ & i.v. & mouse & prevention of MOG-induced EAE [56] \\
\hline
\end{tabular}

$\mathrm{MBP}=$ Myelin basic protein MOG = myelin oligodendrocyte glycoprotein NF- $\mathrm{\kappa B}$ ODN = oligodeoxyribonucleotides encoding for NF- $\mathrm{kB}$ binding sites; p.v. $=$ portal vein $; \mathrm{TCR}=\mathrm{T}$-cell receptor $\mathrm{NOD}=$ non-obese diabetic.

petitive experiments with a non-immunosuppressive cyclophilin-binding derivative of CsA have suggested that the immunosuppressive activity of SFA is not dependent on cyclophilin binding [42]. In addition, SFA does not bind to FK506 binding protein 12 (FKBP12) and does not inhibit enzymatic activity of $\mathrm{p} 70^{\mathrm{s} 6 \mathrm{k}}$ kinase, a major downstream target of mTOR $[42,43]$. These results suggest that SFA represents a novel class of immunophilin-binding immunosuppressants with a new, yet undefined mode of action. Studies of the immunosuppressive effects of SFA have been focused on $\mathrm{T}$ and B lymphocytes. SFA has been reported to exhibit a lower immunosuppressive activity in the mixed leukocyte reaction (MLR) than CsA [40]. Recently, we discovered that SFA rapidly blocks bioactive IL-12 production by human DC. In direct comparison to the related agents CsA and rapamycin, we found that SFA acts uniquely within $1 \mathrm{~h}$ inhibiting 80-95\% of DC IL-12p70 production [44]. Additionally, Woltman et al. [45] reported that SFA potently inhibits DC antigen uptake receptor expression and DC endocytosis.

\section{Prevention and Treatment of Experimental Transplant Rejection and Autoimmune Diseases with DC}

Evidence for the tolerogenic ability of DC, either as immature cells or semi-mature cells, was provided by studies in which DC were administered to non-immunosuppressed patients prior to transplantation or tested in models of autoimmune disease (table 1). These studies have demonstrated that DC of donor or recipient origin can prolong heart, kidney or pancreatic islet allograft survival [46-52]. Autologous DC - with or without autoantigen pulsing - inhibit the development of experimental allergic encephalomyelitis (EAE) or type-1 diabetes [53-55] (table 1).
A growing number of reports have described the immunoregulatory capacity of semi-mature DC. Menges et al. [56] demonstrated that repeated injections of DC matured with TNF- $\alpha$ induced IL-10-producing peptide-specific T cells in vivo and antigen-specific protection from experimental autoimmune encephalomyelitis, which was not the case with immature DC or DC matured with lipopolysaccharide (LPS) and CD40L. The tolerogenic DC were characterized as MHC II ${ }^{\text {high }}$ and costimulatory ${ }^{\text {high }}$, but were found to be weak producers of proinflammatory IL-12p70 compared to LPS/CD40L matured DC. A similar approach was successfully employed by Sato et al. $[57,58]$ who expanded DC in the presence of IL-10 and transforming growth factor beta (TGF- $\beta$ ) and matured these APC with either LPS or TNF- $\alpha$. These semi-mature DC expressed high levels of MHC II ${ }^{\text {high }}$ and low levels of costimulatory molecules, and it is conceivable (although not having been directly investigated) that these DC were low producers of proinflammatory cytokines. By using a murine model for graft-versus-host disease (GVHD) and leukemia relapse, it was demonstrated that host-matched semi-mature DC protected the mice in an antigen-specific manner from GVHD lethality and induced expansion of IL-10-producing CD4+ CD25+ suppressor T cells [57]. Treatment with semi-mature DC retained the graft-versus-leukemia (GVL) effect in recipients of allogeneic bone marrow and spleen mononuclear cells. However, without abrogating the GVL effect, the underlying mechanisms of GVDH protection are yet to be resolved.

Several investigators have used DC together with immunosuppressive treatment of the recipient. In particular, the blockade of the CD40-CD154 signaling pathway using antiCD154 monoclonal antibodies is highly synergistic with DC therapy [59]. The value of blocking the CD40 pathway is highlighted by the fact that this strategy promotes skin allograft survival even in combination with Flt3L expanded donor DC 
[60]. Interestingly, with respect to chronic rejection of murine heart transplants, we found that the blockade of the CD40CD40L pathway ameliorated transplant vasculopathy, while preservation of near-normal vessel architecture was achieved by simultaneous administration of donor DC [61].

\section{Conclusion}

In recent years, many groups worldwide have generated important insights into the specific effects of classical and novel immunosuppressive agents on key aspects of DC function and activation. Further experimental and pre-clinical studies are now necessary in order to identify the most promising agents and protocols suitable for the generation of tolerogenic DC.

\section{Acknowledgements}

The author's work is supported by grants from the 'Stiftung Hämotherapie Forschung', Bonn, Germany, the Roche Organ Transplantation Research Foundation; Switzerland and the German Science Foundation (DFG, Sonderforschungsbereich 547-A2).

\section{References}

1 Banchereau J, Briere F, Caux C, Davoust J, Lebecque S, Liu YJ, Pulendran B, Palucka K: Immunobiology of dendritic cells. Annu Rev Immunol 2000;18:767-811.

2 Raimondi G, Thomson AW: Dendritic cells, tolerance and therapy of organ allograft rejection. Contrib Nephrol 2005;146:105-120.

3 Morelli AE, Thomson AW: Dendritic cells: regulators of alloimmunity and opportunities for tolerance induction. Immunol Rev 2003;196:125-146.

4 Sallusto F, Cella M, Danieli C, Lanzavecchia A: Dendritic cells use macropinocytosis and the mannose receptor to concentrate macromolecules in the major histocompatibility complex class II compartment: downregulation by cytokines and bacterial products. J Exp Med 1995;182:389-400.

$\checkmark 5$ Lutz MB, Schuler G: Immature, semi-mature and fully mature dendritic cells: which signals induce tolerance or immunity? Trends Immunol 2002;23: 445-449.

6 Steinman RM, Hawiger D, Nussenzweig MC: Tolerogenic dendritic cells. Annu Rev Immunol 2003;21:685-711.

7 Jonuleit H, Schmitt E, Steinbrink K, Enk AH: Dendritic cells as a tool to induce anergic and regulatory T cells. Trends Immunol 2001;22:394-400.

8 Jonuleit H, Schmitt E, Schuler G, Knop J, Enk AH: Induction of interleukin 10-producing, nonproliferating CD4(+) $\mathrm{T}$ cells with regulatory properties by repetitive stimulation with allogeneic immature human dendritic cells. J Exp Med 2000;192:1213 1222

9 Dhodapkar MV, Steinman RM, Krasovsky J, Munz C, Bhardwaj N: Antigen-specific inhibition of effector $\mathrm{T}$ cell function in humans after injection of immature dendritic cells. J. Exp. Med. 2001;193:233238.

10 Hackstein H, Thomson AW: Dendritic cells emerging pharmacological targets of immunosuppressive drugs. Nature Rev Immunol 2004;4:24-35.

11 Penna G, Adorini L: 1 Alpha,25-dihydroxyvitamin D3 inhibits differentiation, maturation, activation, and survival of dendritic cells leading to impaired alloreactive T cell activation. J Immunol 2000;164: 2405-2411.

-12 Berer A, Stockl J, Majdic O, Wagner T, Kollars M, Lechner K, Geissler K, Oehler L: 1,25-Dihydroxyvitamin $\mathrm{D}(3)$ inhibits dendritic cell differentiation and maturation in vitro. Exp Hematol 2000;28:575583.

13 Piemonti L, Monti P, Sironi M, Fraticelli P, Leone BE, Dal Cin E, Allavena P, Di Carlo V: Vitamin D3 affects differentiation, maturation, and function of human monocyte-derived dendritic cells. J Immunol 2000;164:4443-4451.
14 Griffin MD, Lutz WH, Phan VA, Bachman LA, McKean DJ, Kumar R: Potent inhibition of dendritic cell differentiation and maturation by vitamin D analogs. Biochem Biophys Res Commun 2000;270: 701-708

15 Griffin MD, Lutz W, Phan VA, Bachman LA, McKean DJ, Kumar R: Dendritic cell modulation by 1 Alpha,25-dihydroxyvitamin D3 and its analogs: a vitamin D receptor-dependent pathway that promotes a persistent state of immaturity in vitro and in vivo. Proc Natl Acad Sci U S A 2001; 98:6800-6805.

16 Matasic R, Dietz AB, Vuk-Pavlovic S: Cyclooxygenase-independent inhibition of dendritic cell maturation by aspirin. Immunology 2000;101:53-60.

17 Hackstein H, Morelli AE, Larregina AT, Ganster RW, Papworth GD, Logar AJ, Watkins SC, Falo LD, Thomson AW: Aspirin inhibits in vitro maturation and in vivo immunostimulatory function of murine myeloid dendritic cells. J Immunol 2001; 166:7053-7062.

18 Matasic R, Dietz AB, Vuk-Pavlovic S: Dexamethasone inhibits dendritic cell maturation by redirecting differentiation of a subset of cells. J Leukoc Biol 1999;66:909-914.

19 Woltman AM, de Fijter JW, Kamerling SW, Paul LC, Daha MR, van Kooten C: The effect of calcineurin inhibitors and corticosteroids on the differentiation of human dendritic cells. Eur J Immunol 2000;30:1807-1812.

20 Moser M, De Smedt T, Sornasse T, Tielemans F, Chentoufi AA, Muraille E, Van Mechelen M, Urbain J, Leo O: Glucocorticoids down-regulate dendritic cell function in vitro and in vivo. Eur J Immunol 1995:25:2818-2824

21 Vieira PL, Kalinski P, Wierenga EA, Kapsenberg ML, de Jong EC: Glucocorticoids inhibit bioactive IL-12p70 production by in vitro-generated human dendritic cells without affecting their T cell stimulatory potential. J Immunol 1998;161:5245-5251.

22 Matyszak MK, Citterio S, Rescigno M, RicciardiCastagnoli P: Differential effects of corticosteroids during different stages of dendritic cell maturation. Eur J Immunol 2000;30:1233-1242.

23 Sintchak MD, Fleming MA, Futer O, Raybuck SA, Chambers SP, Caron PR, Murcko MA, Wilson KP: Structure and mechanism of inosine monophosphate dehydrogenase in complex with the immunosuppressant mycophenolic acid. Cell 1996;85:921930.

24 Suthanthiran M, Morris RE, Strom TB. Immunosuppressants: cellular and molecular mechanisms of action. Am J Kidney Dis 1996;28:159-172.
25 Mehling A, Grabbe S, Voskort M, Schwarz T, Luger TA, Beissert S: Mycophenolate mofetil impairs the maturation and function of murine dendritic cells. J Immunol 2000;165:2374-2381.

26 Colic M, Stojic-Vukanic Z, Pavlovic B, Jandric D, Stefanoska I: Mycophenolate mofetil inhibits differentiation, maturation and allostimulatory function of human monocyte-derived dendritic cells. Clin Exp Immunol 2003;134:63-69.

27 Lee JI, Ganster RW, Geller DA, Burckart GJ, Thomson AW, Lu L. Cyclosporine A inhibits the expression of costimulatory molecules on in vitrogenerated dendritic cells: association with reduced nuclear translocation of nuclear factor kappa B. Transplantation 1999;68:1255-1263.

28 Peguet-Navarro J, Slaats M, Thivolet J: Lack of demonstrable effect of cyclosporin A on human epidermal Langerhans cell function. Arch Dermatol Res 1991;283:198-202.

29 Chen T, Guo J, Yang M, Han C, Zhang M, Chen W, Liu Q, Wang J, Cao X. Cyclosporin A impairs dendritic cell migration by regulating chemokine receptor expression and inhibiting cyclooxygenase-2 expression. Blood 2004;103:413-421.

30 Morelli AE, Antonysamy MA, Takayama T, Hackstein H, Chen Z, Qian S, Zurowski NB, Thomson AW: Microchimerism, donor dendritic cells, and alloimmune reactivity in recipients of Flt 3 ligandmobilized hemopoietic cells: modulation by tacrolimus. J Immunol 2000;165:226-237.

31 Duperrier K, Velten FW, Bohlender J, Demory A, Metharom P, Goerdt S: Immunosuppressive agents mediate reduced allostimulatory properties of myeloid-derived dendritic cells despite induction of divergent molecular phenotypes. Mol Immunol 2005;42:1531-1540.

32 Tiefenthaler M, Hofer S, Ebner S, Ivarsson L, Neyer S, Herold M, Mayer G, Fritsch P, Heufler C In vitro treatment of dendritic cells with tacrolimus: impaired T-cell activation and IP-10 expression. Nephrol Dial Transplant 2004;19:553-560.

33 Kahan BD, Camardo JS: Rapamycin: clinical results and future opportunities. Transplantation 2001;72:1181-1193.

34 Sehgal SN: Rapamune (RAPA, rapamycin, sirolimus): mechanism of action immunosuppressive effect results from blockade of signal transduction and inhibition of cell cycle progression. Clin Biochem 1998;31:335-340.

35 Raught B, Gingras AC, Sonenberg N: The target of rapamycin (TOR) proteins. Proc Natl Acad Sci U S A 2001;98:7037-7044. 
36 Woltman AM, de Fijter JW, Kamerling SW, van Der Kooij SW, Paul LC, Daha MR, van Kooten C: Rapamycin induces apoptosis in monocyte- and CD34-derived dendritic cells but not in monocytes and macrophages. Blood 2001;98:174-180.

37 Monti P, Mercalli A, Leone E, DiCarlo V, Allavena P, Piemonti L: Rapamycin impairs antigen uptake of human dendritic cells. Transplantation 2003;75: 137-145.

- 38 Hackstein H, Taner T, Zahorchak AF, Morelli AE, Logar AJ, Gessner A, Thomson AW: Rapamycin inhibits IL-4-induced dendritic cell maturation in vitro and dendritic cell mobilization and function in vivo. Blood 2003;101:4457-4463.

39 Hackstein H, Taner T, Logar AJ, Thomson AW: Rapamycin inhibits macropinocytosis and mannose receptor-mediated endocytosis by bone marrow-derived dendritic cells. Blood 2002;100:1084-1087.

-40 Sanglier JJ, Quesniaux V, Fehr T, Hofmann H, Mahnke M, Memmert K, Schuler W, Zenke G, Gschwind L, Maurer C, Schilling W: Sanglifehrins A, B, C and D, novel cyclophilin-binding compounds isolated from Streptomyces sp. A92308110. I. Taxonomy, fermentation, isolation and biological activity. J Antibiot (Tokyo) 1999;52: 466-473.

41 Fehr T, Kallen J, Oberer L, Sanglier JJ, Schilling W: Sanglifehrins A, B, C and D, novel cyclophilinbinding compounds isolated from Streptomyces sp. A92-308110. II. Structure elucidation, stereochemistry and physico-chemical properties. J Antibiot (Tokyo) 1999:52:474-479.

42 Zenke G, Strittmatter U, Fuchs S, Quesniaux VF, Brinkmann V, Schuler W, Zurini M, Enz A, Billich A, Sanglier JJ, Fehr T: Sanglifehrin A, a novel cyclophilin-binding compound showing immunosuppressive activity with a new mechanism of action. J Immunol 2001;166:7165-7171.

43 Zhang LH, Liu JO: Sanglifehrin A, a novel cyclophilin-binding immunosuppressant, inhibits IL-2-dependent $\mathrm{T}$ cell proliferation at the G1 phase of the cell cycle. J Immunol 2001;166:5611-5618.

44 Steinschulte C, Taner T, Thomson AW, Bein G, Hackstein H: Cutting edge: Sanglifehrin A, a novel cyclophilin-binding immunosuppressant blocks bioactive IL-12 production by human dendritic cells. J Immunol 2003;171:542-546.
45 Woltman AM, Schlagwein N, van der Koij SW, van Kooten C: The novel cyclophilin-binding drug Sanglifehrin A specifically affects antigen uptake receptor expression and endocytic capacity of human dendritic cells. J Immunol 2004;172:6482-6489.

46 Lutz MB, Suri RM, Niimi M, Ogilvie AL, Kukutsch NA, Rossner S, Schuler G, Austyn JM: Immature dendritic cells generated with low doses of GMCSF in the absence of IL-4 are maturation resistant and prolong allograft survival in vivo. Eur J Immunol 2000;30:1813-1822.

47 Giannoukakis N, Bonham CA, Qian S, Zhou Z, Peng L, Harnaha J, Li W, Thomson AW, Fung JJ, Robbins PD, Lu L: Prolongation of cardiac allograft survival using dendritic cells treated with NF$\kappa \mathrm{B}$ decoy oligodeoxyribonucleotides. Mol Ther 2000;1:430-437.

48 Min WP, Gorczynski R, Huang XY, Kushida M, Kim P, Obataki M, Lei J, Suri RM, Cattral MS: Dendritic cells genetically engineered to express Fas ligand induce donor-specific hyporesponsiveness and prolong allograft survival. J Immunol 2000;164:161-167.

49 Fu F, Li Y, Qian S, Lu L, Chambers F, Starzl TE, Fung JJ, Thomson AW: Costimulatory moleculedeficient dendritic cell progenitors (MHC class II+, CD80dim, CD86-) prolong cardiac allograft survival in nonimmunosuppressed recipients. Transplantation 1996;62:659-665.

50 Taner T, Hackstein H, Wang Z, Morelli AE, Thomson AW: Rapamycin-treated, alloantigen-pulsed host dendritic cells induce Ag-specific T cell regulation and prolong graft survival. Am J Transplant 2005;5:228-236.

51 Gorczynski RM, Bransom J, Cattral M, Huang X, Lei J, Xiaorong L, Min WP, Wan Y, Gauldie J: Synergy in induction of increased renal allograft survival after portal vein infusion of dendritic cells transduced to express TGFbeta and IL-10, along with administration of $\mathrm{CHO}$ cells expressing the regulatory molecule OX-2. Clin Immunol 2000;95: 182-189.

52 O'Rourke RW, Kang SM, Lower JA, Feng S, Ascher NL, Baekkeskov S, Stock PG: A dendritic cell line genetically modified to express CTLA4-IG as a means to prolong islet allograft survival. Transplantation 2000;69:1440-1446.
53 Huang YM, Yang JS, Xu LY, Link H, Xiao BG: Autoantigen-pulsed dendritic cells induce tolerance to experimental allergic encephalomyelitis (EAE) in lewis rats. Clin Exp Immunol 2000;122:437-444.

54 Feili-Hariri M, Dong X, Alber SM, Watkins SC, Salter RD, Morel PA: Immunotherapy of NOD mice with bone marrow-derived dendritic cells. Diabetes 1999;48:2300-2308

55 Shinomiya M, Fazle Akbar SM, Shinomiya H, Onji M: Transfer of dendritic cells (DC) ex vivo stimulated with interferon-gamma (IFN-gamma) downmodulates autoimmune diabetes in non-obese diabetic (NOD) mice. Clin Exp Immunol 1999;117: 38-43.

56 Menges M, Rossner S, Voigtlander C, Schindler H, Kukutsch NA, Bogdan C, Erb K, Schuler G, Lutz MB: Repetitive injections of dendritic cells matured with tumor necrosis factor alpha induce antigen-specific protection of mice from autoimmunity J Exp Med 2002;195:15-21.

57 Sato K, Yamashita N, Baba M, Matsuyama T: Regulatory dendritic cells protect mice from murine acute graft-versus-host disease and leukemia relapse. Immunity 2003;18:367-379.

58 Sato K, Yamashita N, Baba M, Matsuyama T. Modified myeloid dendritic cells act as regulatory dendritic cells to induce anergic and regulatory T cells. Blood 2003;101:3581-3589.

59 Lu L, Li W, Fu F, Chambers FG, Qian S, Fung JJ, Thomson AW: Blockade of the CD40-CD40 ligand pathway potentiates the capacity of donor-derived dendritic cell progenitors to induce long-term cardiac allograft survival. Transplantation 1997;64: 1808-1815.

60 Markees TG, Phillips NE, Gordon EJ, Noelle RJ, Maliszewski C, Mordes JP, Greiner DL, Rossini AA: Prolonged skin allograft survival in mice treated with Flt3-ligand-induced dendritic cells and antiCD154 monoclonal antibody. Transplant Proc 1999; 31:884-885.

61 Wang Z, Morelli AE, Hackstein H, Kaneko K, Thomson AW: Marked inhibition of transplant vascular sclerosis by in vivo-mobilized donor dendritic cells and anti-CD154 mAb. Transplantation 2003; 76:562-571.

62 Kim SH, Kim S, Evans CH, Ghivizzani SC, Oligino T, Robbins PD: Effective treatment of established murine collagen-induced arthritis by systemic administration of dendritic cells genetically modified to express IL-4. J. Immunol. 2001;166:3499-3505. 